\title{
Effect of Premedication with Clonidine vs. Atenolol in Providing Optimum Surgical Field in Spine Fusion Surgery Under General Anaesthesia
}

\author{
MAHMOUD A. ALI, M.D.; NAGWA M. IBRAHIM, M.D. and SABRY MAHDY, M.Sc. \\ The Department of Anaesthesiology, ICU \& Pain Management, Faculty of Medicine, Assiut University, Assiut, Egypt
}

\begin{abstract}
Background: Spine surgeries are associated with significant blood loss, which vary from 10 to $30 \mathrm{~mL} / \mathrm{kg}$ and its volume depends on the number of spinal levels fused; body weight, surgery for tumors, and raised intra-abdominal pressure in the prone position. Blood loss can be an acute problem not only in major deformity surgery but also in less extensive fusion procedures. Controlled hypotension is among the most widely used techniques for reducing blood loss in various types of surgery including spine surgery.
\end{abstract}

Aim of Study: The aim of the work was to evaluate the effect of preoperative clonidine vs. Atenolol on providing optimum surgical field in patients undergoing spine fusion surgery, and to minimize intraoperative blood loss and lastly for assessment of intraoperative surgeon satisfaction.

Patients and Methods: This study was prospective double blinded randomized clinical trial, was conducted in Orthopedic Operative Rooms in Assiut University Hospitals on patients underwent spine fusion surgery. It was done from April 2016 till April 2017. Sixty patients (ASA I or II) were undergone elective spine fusion surgery were included in this study. Patients were randomly divided into three Groups I, II, III. Group 1 (control group), patients received oral placebo. Group II (Atenolol group), patients received oral Atenolol tablet $50 \mathrm{mg}$, Group III (clonidine group), patients received oral clonidine tablet 100ug. These drugs were given to the patients $2 \mathrm{hr}$ before induction of anesthesia. The hemodynamic parameters like Heart Rate (HR), Mean Arterial Blood Pressure (MAP), oxygen saturation (SPO2\%) were checked intra and post operatively, intra-operative bleeding was measured, and the surgeon unaware of the group was asked to evaluate the quality of the operative field using the pre-defined Average Category Scale (ACS) at the end of surgical procedure.

Results: Both intra and post-operative Heart Rate (HR), Mean Arterial Blood Pressure (MAP) were more reduced in Group II than in Group III than in Group I. Intraoperative blood loss and need for blood transfusion were less in Group II than in Group III than in Group I. The field was much better in Group II than in Group III than in Group I.

Correspondence to: Dr. Mahmoud A. Ali, The Department of Anaesthesiology, ICU \& Pain Management, Faculty of Medicine, Assiut University, Assiut, Egypt
Conclusion: This study concluded that both clonidine and atenolol were effective and safe, in terms of stable hemodynamic profile and reducing intraoperative bleeding; when given orally to patients as premedication in patients for spine surgeries under general anesthesia. However, out of the two drugs atenolol appeared to be better in terms of reduction of blood loss and providing good quality of surgical field when compared to clonidine.

Key Words: Spine fusion surgery - Atenolol-Clonidine.

\section{Introduction}

BLOOD loss in spine surgery has a significant impact on patient morbidity, length of surgery, and total cost. In addition to maintain patient's hemodynamics, the control of blood loss is essential in attaining adequate visualization of the surgical field. Due to the proximity of tenuous neurovascular structures, the importance of a dry surgical field cannot be overemphasized. Realizing this goal requires collaboration between surgical and anesthetic teams [1]

Decreased bleeding reduces the need for the transfusion of blood products, thereby reducing the risk of complications, such as hemolytic and non-hemolytic reactions, acute lung injury, transmission of viral and bacterial infections, hypothermia, and coagulation disorders. Blood-sparing techniques can be divided into two groups, based on their goals: They are aimed at decreasing the bleeding itself [hemodynamically (e.g., controlled hypotension, local vasoconstrictors, epidural blockade) or with chemical/biological agents (e.g., desmopressin, aprotinin, tranexamic acid, epsilonaminocaproic acid, estrogens, bone wax, hemostatic "sponges," fibrin sealants)] or at decreasing the need for homologous transfusion (e.g., acute hemodilution, planned autologous transfusion, cellsaving systems, erythropoietin). Controlled hypotension has been used with success in Orthopedic 
Surgery. It is applied widely in spine surgery, and several studies have demonstrated it to be useful in spine surgery [2-5].

The exact mechanism by which controlled hypotension decreases blood loss is still unclear. Some authors have hypothesized that hypotensive anesthesia gives rise to an ischemic wound, which then causes less blood loss [6].

Agents that are used alone to induce controlled hypotension include inhalation anesthetics, sodium nitroprusside, nitroglycerin, trimethaphan, alprostadil (prostaglandin E1), adenosine, remifentanil, and agents that are used in spinal anaesthesia. Agents that can be used alone or as adjuvants include calcium channel antagonists (e.g., nicardipine), beta-adrenoceptor antagonists (e.g., propranolol, esmolol), and fenoldopam. Agents that are primarily used adjunctively include Angiotensin Converting Enzyme (ACE) inhibitors and clonidine [7-11]

\section{Objectives:}

This study was conducted to evaluate the effect of preoperative clonidine vs. Atenolol on providing optimum surgical field in patients undergoing spine fusion surgery, and to minimize intraoperative blood loss and lastly for assessment of intraoperative surgeon satisfaction.

\section{Patients and Methods}

\section{Eligibility and randomization:}

After approval from the Local Ethics Committee of Faculty of Medicine, Assiut University, written informed consent from all patients before participation was obtained. The study started on April 2016 and finished on April 2017.

\section{Confidentiality and Ethical consideration:}

All data taken from all participants in this research work either from history, examination or investigations were dealt with in a confidential manner. There was no risk affecting patients in the study.

\section{Setting:}

Orthopedic Operative Rooms in Assiut University Hospitals.

\section{Study design:}

This study was a prospective double blinded randomized clinical trial. It was carried out on sixty patients (ASA I or II) 18-60 years old of both sex underwent elective spine fusion surgery under general anesthesia were included in the study.
Neither the investigator nor the participant was aware of the group allocation or the drug used. The drugs used were prepared by one of the supervisor anesthesiologists (not included in the procedure, observation or in the data collection).

\section{Patients:}

Sixty patients were randomly divided into three equal groups of 20 patients each: Control Group I in which patients received oral tab placebo, Atenolol Group II in which patients received oral tab atenolol 50mg, and Clonidine Group III in which patients received oral tab clonidine 100ug. These drugs were given to the patients $2 \mathrm{hr}$ before induction of anesthesia by number coded envelops.

\section{Inclusion criteria:}

Age 18 to 60 years, ASA physical status I-II, scheduled for elective spine fusion surgery under general anesthesia.

\section{Exclusion criteria:}

Patient refusal, patients who have history of bronchial asthma, Chronic Obstructive Pulmonary Disease (COPD), diabetes mellitus, hypertension, bleeding tendency, coagulation disorders, morbid obesity, those with history of hypersensitivity reaction to study drugs are being excluded from the study.

\section{Anesthesia technique:}

On arrival to the operative room after attaching standard monitoring, appropriate sized cannula was inserted and intravenous line started with normal saline or Ringer's lactate solutions $20 \mathrm{ml} / \mathrm{kg}$ with considering replacement of losses accordingly. Pre-oxygenation with $100 \%$ oxygen was started for 2-3 minutes. Patients received fentanyl $2 \mathrm{ug} / \mathrm{kg}$ before induction. Induction was continued with propofol $1.5-2.5 \mathrm{mg} / \mathrm{kg}$ plus cisatracurium 0.15 $0.2 \mathrm{mg} / \mathrm{kg}$ followed by intubation with appropriate sized endotracheal tube. Anesthesia was maintained by isoflourane inhalation of 1.5 MAC (Minimum Alveolar Concentration) plus cisatracurium of 0.02$0.03 \mathrm{mg} / \mathrm{kg}$ direct IV injection every $1 / 2 \mathrm{hr}$ (fixed interval). Controlled mechanical ventilation with initial tidal volume of $8 \mathrm{ml} / \mathrm{kg}$ and respiratory frequency of 12 breaths/min is adjusted to maintain end tidal carbon dioxide between $30-35 \mathrm{mmHg}$. After the end of the procedure that took from 90120 minutes and after return of patient breathing, reversal of neuromuscular blockade was achieved using neostigmine $0.05 \mathrm{mg} / \mathrm{kg}+$ atropine $1 \mathrm{mg} \mathrm{am}$ poule. When the patient started to obey commands extubation was done, as the patient becomes fully conscious was shifted to recovery room. 
Data monitoring and collection (pre, intra, and post-operative):

- The hemodynamic parameters like Heart Rate (HR), Mean Arterial Blood Pressure (MAP), oxygen saturation (SPO2\%) were checked before (Tb) and after (Ti) induction, immediately after intubation (T0), then every 5 minutes for 15 minutes and then every 15 minutes till end of surgery, then every 15 minutes for $1 \mathrm{hr}$ in the recovery room.

- Intra-operative bleeding was measured by collecting blood in a marked Container of $2 \mathrm{~L}$ capacity. The blood soaked by towels was measured by weighing the towel pieces before autoclaving and after the surgical procedure.

- The surgeon unaware of the group was asked to evaluate the quality of the operative field using the pre-defined Average Category Scale (ACS) grading at the end of surgical procedure.

\section{Average Category Scale (ACS) grading:}

Grade:

1- Slight bleeding-no suctioning required.

2- Slight bleeding-occasional suctioning required. Surgical field not threatened.

3- Slight bleeding-frequent suctioning required. Bleeding threatens surgical field a few seconds after suction is removed.

4- Moderate bleeding-frequent suctioning required. Bleeding threatens surgical field directly after suction is removed.
5- Severe bleeding-constant suction required. Bleeding appears faster that can be removed by suction. Surgical field severely threatened and surgery not possible.

Surgical field was graded as good-ACS 0 or 1 , fair--ACS 2 or 3, poor-ACS 4 or 5 .

\section{Statistical analysis:}

Collected data were analyzed using the statistical package SPSS Version 20. Data with a continuous variation were expressed as mean \pm SD. Differences were considerd statistically significant if $p$-value is less than 0.05 .

\section{Results}

Sixty patients ASA state (I-II) underwent spine fusion surgery were included in the study and were divided into three Groups I, II, III, 20 patients each. All were blindly given Placebo, Atenolol and Clonidine in order. There were no statistically significant differences between groups as regard patients' demographic data, and intraoperative saturation (SPO2\%). Both intraoperative and postoperative Heart Rate (HR) and Mean Arterial Blood Pressure (MAP) were more significantly decreased in Atenolol Group II than in clonidine Group III than in control Group I. (Tables 1,2) \& Figs. $(1,2)$. As regard blood loss and the need for blood transfusion both were significantly decreased in Group II than in Group III than in Group I. (Tables 3,4) $\&$ Figs. $(3,4)$, as regard surgeon opinion the field was much better in Group II than in Group III than in Group I. (Table 5) \& Fig. (5).

Table (1): Intraoperative heart rate (beat $/ \mathrm{min}$ ).

\begin{tabular}{lllllll}
\hline \multicolumn{7}{c}{ Group } \\
\cline { 2 - 4 } & \multicolumn{1}{c}{$\begin{array}{c}\text { Group I } \\
\text { Mean } \pm \text { SD }\end{array}$} & $\begin{array}{c}\text { Group II } \\
\text { Mean } \pm \text { SD }\end{array}$ & $\begin{array}{c}\text { Group III } \\
\text { Mean } \pm \text { SD }\end{array}$ & $p_{1}$ & $p_{2}$ & $p_{3}$ \\
\hline Before induction & $90.55 \pm 13$ & $68.9 \pm 12.21$ & $80.9 \pm 12.69$ & $0.000^{* *}$ & $0.019^{*}$ & $0.004^{* *}$ \\
After induction & $80.75 \pm 12.57$ & $64.9 \pm 7.34$ & $70.45 \pm 11.82$ & $0.000^{* *}$ & $0.004^{* *}$ & 0.110 \\
After intubation & $100.1 \pm 17.49$ & $82.1 \pm 9.66$ & $89.8 \pm 15.54$ & $0.000^{* *}$ & $0.030^{*}$ & 0.101 \\
After 5 main & $92.8 \pm 16$ & $72.8 \pm 12.79$ & $80.35 \pm 15.81$ & $0.000^{* *}$ & $0.011^{*}$ & 0.116 \\
After10 main & $87.15 \pm 14.47$ & $68.3 \pm 10.48$ & $80.05 \pm 16.18$ & $0.000^{* *}$ & 0.112 & $0.010^{* *}$ \\
After15 main & $86.1 \pm 14.6$ & $68.55 \pm 11.61$ & $77.75 \pm 16.21$ & $0.000^{* *}$ & 0.069 & $0.046^{*}$ \\
After 30 main & $81.8 \pm 16.38$ & $65.3 \pm 12.44$ & $74.05 \pm 15.66$ & $0.001 * *$ & 0.106 & 0.069 \\
After 45 main & $78.75 \pm 16.1$ & $61.9 \pm 9.71$ & $72.45 \pm 13.45$ & $0.000^{* *}$ & 0.141 & $0.015^{*}$ \\
After 60 main & $83.25 \pm 13.64$ & $62.65 \pm 9.51$ & $71.15 \pm 14.78$ & $0.000^{* *}$ & $0.004^{* *}$ & $0.041^{*}$ \\
After 75 main & $82.3 \pm 11.59$ & $62.4 \pm 9.09$ & $70.9 \pm 14.43$ & $0.000^{* *}$ & $0.004^{* *}$ & $0.028^{*}$ \\
After 90 main & $80.7 \pm 16.79$ & $61.25 \pm 9.27$ & $71.15 \pm 13.08$ & $0.000^{* *}$ & $0.028^{*}$ & 0.023 \\
After 105 main & $80.2 \pm 16.03$ & $63.95 \pm 8.91$ & $71.25 \pm 13.77$ & $0.000^{* *}$ & $0.037^{*}$ & 0.087 \\
After 120 main & $80.81 \pm 16.21$ & $65.76 \pm 8.3$ & $72.3 \pm 13.08$ & $0.002^{* *}$ & 0.054 & 0.130 \\
\hline * : Statistically significant difference $(p<0.05)$. & & & &
\end{tabular}


Table (2): Pre-operative Mean Arterial Pressure (MAP).

\begin{tabular}{lllllll}
\hline & \multicolumn{1}{c}{$\begin{array}{c}\text { Group I } \\
\text { Mean } \pm \text { SD }\end{array}$} & $\begin{array}{c}\text { Group II } \\
\text { Mean } \pm \text { SD }\end{array}$ & $\begin{array}{c}\text { Group III } \\
\text { Mean } \pm \text { SD }\end{array}$ & $p_{1}$ & $p_{2}$ & $p_{3}$ \\
\hline Before induction & $100.2 \pm 9.09$ & $88.15 \pm 13.88$ & $89.75 \pm 14.07$ & $0.004^{* *}$ & $0.011^{*}$ & 0.689 \\
After induction & $71.65 \pm 15.07$ & $56.45 \pm 11.08$ & $64.2 \pm 8.36$ & $0.000^{* *}$ & $0.028^{*}$ & $0.047^{*}$ \\
After intubation & $85.05 \pm 15.24$ & $70.8 \pm 13.15$ & $79.95 \pm 16.29$ & $0.004^{* *}$ & 0.139 & $0.033^{*}$ \\
After 5min & $76.25 \pm 19.58$ & $69.15 \pm 7.51$ & $69.7 \pm 10.48$ & $0.103^{* *}$ & 0.132 & 0.898 \\
After 10min & $77.75 \pm 15.84$ & $67.15 \pm 12.47$ & $74.5 \pm 16.12$ & $0.028^{*}$ & 0.270 & $0.045^{*}$ \\
After 15min & $85.05 \pm 15.65$ & $70.6 \pm 10.87$ & $71.8 \pm 13.5$ & $0.001^{* *}$ & $0.003^{* *}$ & 0.779 \\
After 30min & $85.3 \pm 12.87$ & $67.7 \pm 12.79$ & $67.3 \pm 9.8$ & $0.000^{* *}$ & $0.000^{* *}$ & 0.916 \\
After 45min & $75.35 \pm 17.88$ & $61.2 \pm 13.29$ & $69.1 \pm 11.88$ & $0.011^{*}$ & 0.180 & $0.044^{*}$ \\
After 60min & $78.05 \pm 15.38$ & $61.6 \pm 8.67$ & $68.4 \pm 10.89$ & $0.000^{* *}$ & $0.007^{* *}$ & $0.039^{*}$ \\
After 75min & $75.65 \pm 12.24$ & $63.55 \pm 9.31$ & $67.6 \pm 10.74$ & $0.001^{* *}$ & $0.022^{*}$ & 0.242 \\
After 90min & $78.4 \pm 12.02$ & $64.4 \pm 11.94$ & $66 \pm 8.89$ & $0.000^{* *}$ & $0.001^{* *}$ & 0.649 \\
After 105min & $79.4 \pm 12.68$ & $64.7 \pm 11.64$ & $66.75 \pm 9.44$ & $0.000^{* *}$ & $0.001^{* *}$ & 0.570 \\
After 120min & $75.56 \pm 14.05$ & $66.76 \pm 11.37$ & $67.45 \pm 7.24$ & $0.026^{*}$ & $0.032^{*}$ & 0.851 \\
\hline *: Statistically significant difference $(p<0.05)$. & & & & \\
**: Statistically significant difference $(p<0.01)$. & & & & &
\end{tabular}

Table (3): Blood loss.

\begin{tabular}{ccccccc}
\hline & $\begin{array}{c}\text { Clonidine } \\
\text { Mean } \pm \text { SD }\end{array}$ & $\begin{array}{c}\text { Atenolol } \\
\text { Mean } \pm \text { SD }\end{array}$ & $\begin{array}{c}\text { Control } \\
\text { Mean } \pm \text { SD }\end{array}$ & $p_{1}$ & $p_{2}$ & $p_{3}$ \\
\hline Blood loss & $628.45 \pm 266.69$ & $466.25 \pm 194.93$ & $769.25 \pm 288.33$ & $0.047^{*}$ & 0.084 & $0.000^{* *}$ \\
\hline
\end{tabular}

* : Statistically significant difference $(p<0.05)$

**: Statistically significant difference $(p<0.01)$

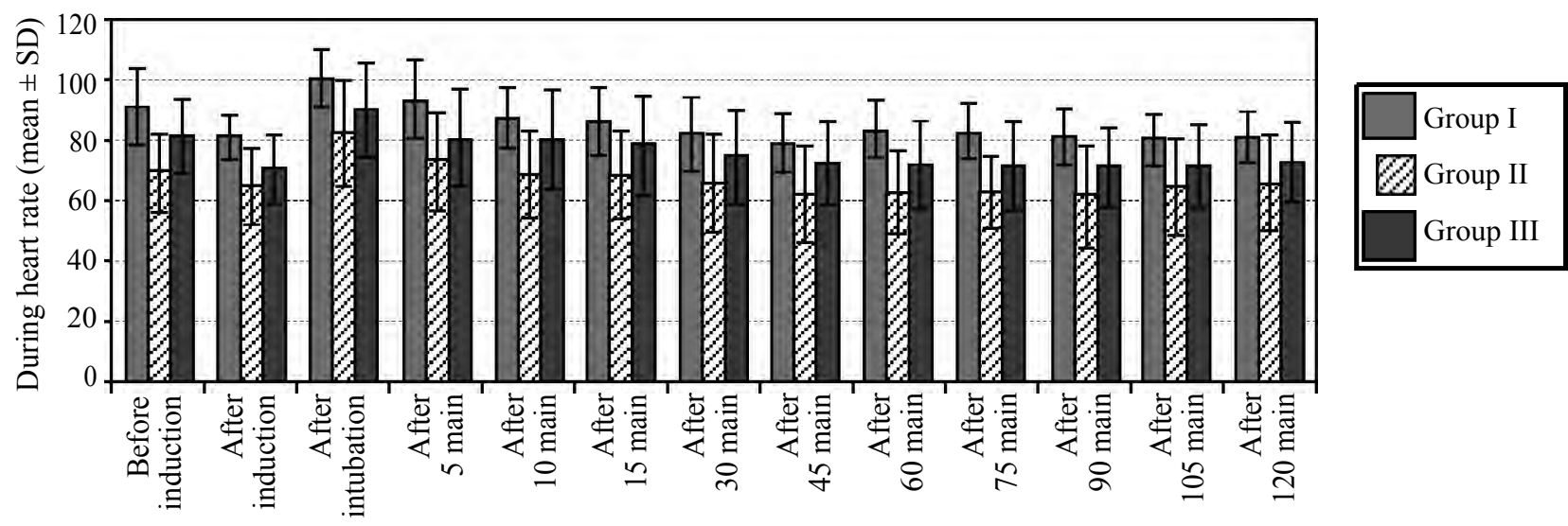

Fig. (1): Intraoperative heart rate.

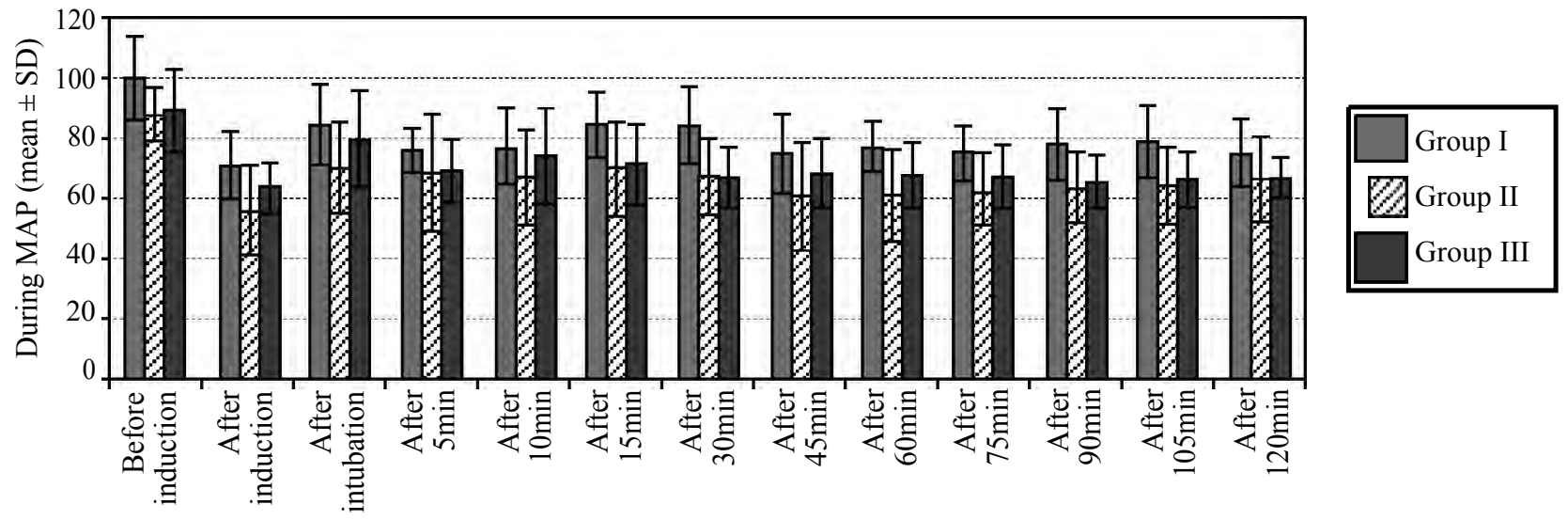

Fig. (2): Intraoperative Mean Arterial Pressure (MAP). 
Table (4): Blood transfusion.

\begin{tabular}{|c|c|c|c|c|c|c|c|}
\hline \multirow{2}{*}{$\begin{array}{l}\text { Blood } \\
\text { transfusion }\end{array}$} & \multicolumn{2}{|c|}{ Clonidine } & \multicolumn{2}{|c|}{ Atenolol } & \multicolumn{2}{|c|}{ Control } & \multirow{2}{*}{$\begin{array}{c}p- \\
\text { value }\end{array}$} \\
\hline & . & $\%$ & $\mathrm{o}$ & $\% 1$ & 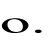 & $\%$ & \\
\hline Yes & 11 & 55.0 & 7 & 35.0 & 15 & 75.0 & $0.039 *$ \\
\hline No & 9 & 45.0 & 13 & 65.0 & 5 & 25.0 & \\
\hline
\end{tabular}

*: Statistically significant difference $(p<0.05)$.

Table (5): Surgeon opinion.

\begin{tabular}{|c|c|c|c|c|c|c|c|}
\hline & \multicolumn{2}{|c|}{ Group I } & \multicolumn{2}{|c|}{ Group II } & \multicolumn{2}{|c|}{ Group III } & \multirow{2}{*}{$\begin{array}{c}p- \\
\text { value }\end{array}$} \\
\hline & No. & $\%$ & No. & $\%$ & No. & $\%$ & \\
\hline Good & 1 & 5.0 & 14 & 70.0 & 8 & 40.0 & $0.000 * *$ \\
\hline Faire & 8 & 40.0 & 5 & 25.0 & 7 & 35.0 & \\
\hline Poor & 11 & 55.0 & 1 & 5.0 & 5 & 25.0 & \\
\hline
\end{tabular}

* : Statistically significant difference $(p<0.05)$

$* *$ : Statistically significant difference $(p<0.01)$.

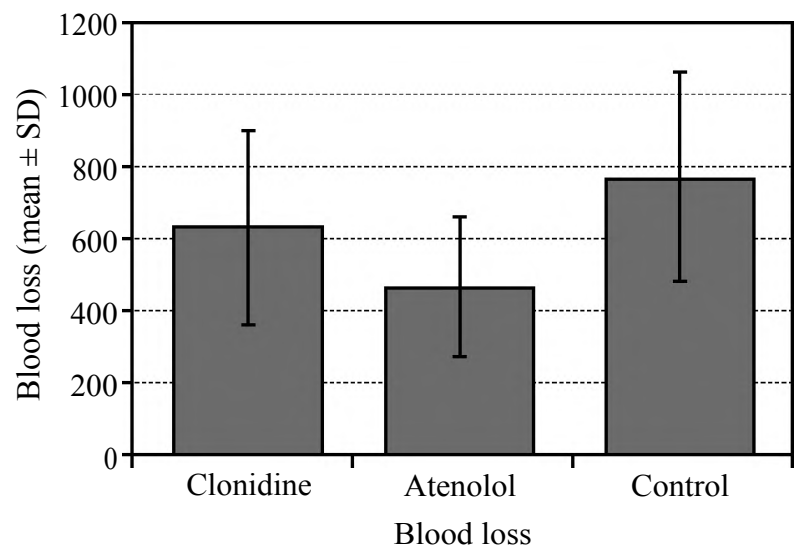

Fig. (3): Intraoperative blood loss.

\section{Discussion}

There are no similar studies done before to compare these two drugs in such type of surgery, but some studies used either clonidine alone or atenolol alone with placebo.

Zahra et al., [12], had used clonidine alone $(3 \mu \mathrm{g} / \mathrm{kg}$ in an adult patient) with placebo in 2 groups 15 patients each. Patients in both groups were nearly received the same of our Anaesthesia regimen plus remifentanil infusion of 0.1 to $1 \mathrm{~g} / \mathrm{k} / \mathrm{min}$, which was titrated to a target MAP of $60-70 \mathrm{mmHg}$. If a $1-\mu \mathrm{g} / \mathrm{kg} / \mathrm{min}$ dose of remifentanil was not enough to induce the target hypotension.

They observed that clonidine group had significantly less intraoperative blood loss compared to the control group. The clonidine group had also less remifentanil use for keeping the MAP in the desired range for controlled hypotension than the control group.

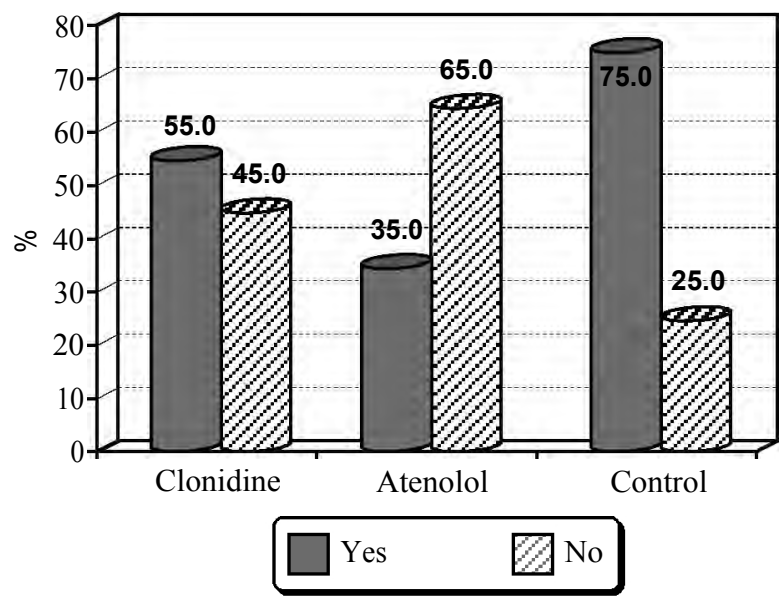

Fig. (4): Intraoperative blood transfusion.

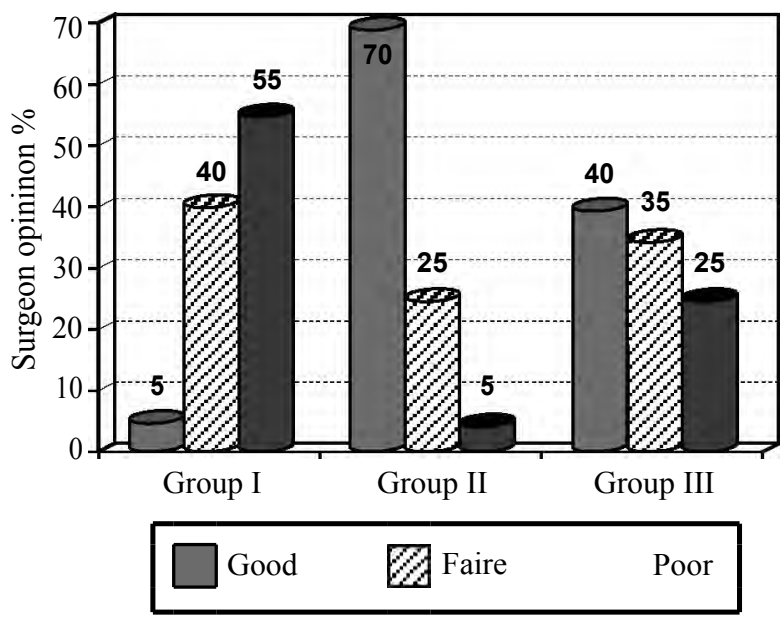

Fig. (5): Surgeon openion.

Surgeon satisfaction for a bloodless field was good in patients in the clonidine group compared to patients in the control group, there was no need for nitroglycerin to maintain controlled hypotension in either group.

In this study clonidine reduced bleeding through mechanisms other than hypotension. Clonidine significantly reduced the dose of remifentanil needed to maintain the same levels of hypotension as the control group. This anesthetic and analgesicsparing effect is a hallmark of clonidine, as shown in nearly all studies of the effects of clonidine in anesthesia with various agents and for various types of surgery.

In the present study results are not coincident with the previous results because we used comparatively a small fixed dose of clonidine $(100 \mu \mathrm{g}$ in all patients), also there is no use of neither remifentanil nor nitroglycerine infusion that may cause more decrease in MAP and less blood loss. 
Yasser and Sabry [13], have used oral atenolol $50 \mathrm{mg}$ with placebo in 2 groups 40 patients each, patients in both groups were received intraoperative sodium nitroprusside SNP infusion by rate of 1$2 \mathrm{pg} / \mathrm{kg} / \mathrm{min}$ as hypotensive agent, they concluded that Premedication with oral atenolol 50mg twice/day for one day before hypotensive anesthesia with SNP during spinal surgeries seems to be clinically safe and effective to reduce heart rate, the amount of SNP used, amount of blood loss, and amount of blood transfused with better quality of surgical field.

Amrinder et al., [14], had clearly compared between the effect of oral clonidine and oral atenolol in providing optimum surgical field during nasal surgery where they used 60 patients ASA I, II divided into 2 groups 30 patients each.one group received oral atenolol $(50 \mathrm{mg})$ and the other group received clonidine $(100 \mathrm{pg})$, the same of our doses and nearly the same of our anesthesia regimen but there was no control group. They concluded that both clonidine and atenolol were effective and safe, in terms of stable hemodynamic profile and reducing intraoperative bleeding; when given orally to patients as premedication in patients for nasal surgeries under general anesthesia. However, out of the two drugs clonidine appeared to be better in terms of reduction of blood loss and providing good quality of surgical field when compared to atenolol.

These results are not coincident with our results because this study was done on patients with nasal surgery in which clonidine may be more effective not only due to its hypotensive action but also due to its sedative, anxiolytic, antinociceptive effect through stimulation of central alpha-2 adrenoceptor at different sites in the central nervous system that result in decreases sympathetic tone and increases vagal activity, which blunts the hemodynamic responses to stressful stimuli.

But our current study done on patients with spine surgery that is richly supplied by blood and blood loss here is more dependant on heart rate, blood pressure which are more affected by atenolol than clonidine. Also in this study there was no control group that makes the comparison deficient.

Bajaj et al., [15], evaluated the efficacy of clonidine in reducing blood loss in pituitary adenoma surgery. They prospectively analyzed 50 patients with pituitary adenomas and randomly divided into two study groups. First group included patients that received clonidine orally, while other group included patients who received placebo.
They observed significant blood loss during surgery in between the patients of the two study groups. Also when compared between the two study groups, statistical significant results were obtained while comparing operative time and bleeding grading by the clinician. From the results, they concluded that in terms of efficacy and safety, clonidine is a safer drug in patients undergoing trans-sphenoidal microscopic pituitary adenoma surgeries.

Matot et al., [16], evaluated and compared the effectiveness of two doses of oral clonidine premedication with placebo. They analyzed 62 patients and randomly divided them into two study groups. Only those patients were included that underwent elective fibreoptic bronchoscopy. They observed that during fibreoptic bronchoscopy, a significant increase in the blood pressure and heart rate were observed in the control group.

From the result, they concluded that attenuated hemodynamic responses to fibreoptic bronchoscopy are observed with oral clonidine.

\section{Conclusion and Recommendations:}

This study concluded that both clonidine and atenolol were effective and safe, in terms of stable hemodynamic profile and reducing intraoperative bleeding; when given orally to patients as premedication in patients for spine surgeries under general anesthesia. However, out of the two drugs atenolol appeared to be better in terms of reduction of blood loss and providing good quality of surgical field when compared to clonidine.

So, we recommend for the routine use of Bblockers especially atenolol tab preoperatively in patients undergoing spine fusion surgery because it is more effective, more available, and cheaper than clonidine.

\section{References}

1- HUR S.R., HUIZENGA B.A. and MAJOR M.: Acute normovolemic hemodilution combined with hypotensive anesthesia and other techniques to avoid homologous transfusion in spinal fusion surgery. Spine, 17 (8): 867 73, 1992.

2- GRUNDY B.L., NASH C.L., Jr. and BROWN R.H.: Deliberate hypotension for spinal fusion: Prospective randomized study with evoked potential monitoring. Can. Anaesth. Soc. J., 29 (5): 452-62, 1982.

3- LEE T.C., YANG L.C. and CHEN H.J.: Effect of patient position and hypotensive anesthesia on inferior vena caval pressure. Spine (Phila Pa 1976), 23 (8): 941-7, 1998.

4- ULLRICH P.F., JR., KEENE J.S., HOGAN K.J. and ROECKER E.B.: Results of hypotensive anesthesia in 
operative treatment of thoracolumbar fractures. J. Spinal Disord., 3 (4): 329-33, 1990.

5- ZPALSKI M., GUNZBURG R. and SZTERN B.: An overview of blood-sparing techniques used in spine surgery during the perioperative period. Eur. Spine J., 13 (Suppl 1): S18-27, 2004.

6- DEGOUTE C.S.: Controlled hypotension: A guide to drug choice. Drugs, 67 (7): 1053-76, 2007.

7- IMANI F., JAFARIAN A., HASSANI V. and KHAN Z.H.: Propofol-alfentanil vs propofol-remifentanil for posterior spinal fusion including wake-up test. Br. J. Anaesth., 96 (5): 583-6, 2006.

8- OKUYAMA K., INOMATA S. and TOYOOKA H.: The effects of prostaglandin E1 or oral clonidine premedication on blood loss during paranasal sinus surgery. Can. J. Anaesth., 52 (5): 546-7, 2005.

9- PARK S.H., DO S.H., KIM C.S., RO Y.J., HAN S.H., KIM J.H., et al.: Controlling deliberate hypotension in hypertensive patients undergoing spinal surgery: A comparison between remifentanil and sodium nitroprusside. Anesth. Pain Med., 5 (1): 38-44, 2010.

10- CHILLEMI S., SINARDI D., MARINO A., MANTARRO G. and CAMPISI R.: The use of remifentanil for bloodless surgical field during vertebral disc resection. Minerva Anestesiol., 68 (9): 645-9, 2002.

11- FRANK T., WEHNER M., HEINKE W. and SCHMADICKE I.: [Clonidine vs. Midazolam for premedica- tion - comparison of the anxiolytic effect by using the STAI-test]. Anasthesiol Intensivmed Notfallmed Schmerzther. 2002;3 7(2):89-93.

12- ZAHRA T.A., NADER A-F, FARNAD I., MOJGAN S., BABAK A. and MASOOD M.: Effect of Clonidine Premedication on Blood Loss in Spine Surgery. Anesth. Pain, 1 (4): 252-6. Doi: 10.5812/ AAPM.2197, 2012.

13- YASSER M.A. and SABRY M.A.: Effects of preoperative (3-blocker on blood loss and blood transfusion during spinal surgeries with sodium nitroprusside-controlled hypotension, 2011.

14- AMRINDER S., RUCHI G., TRIPAT B., ANURADHA A. and VANITA S.: A Study to Evaluate the Effectiveness of Clonidine vs Atenolol in ProvidingOptimal Surgical Field in Nasal Surgeries under General Anaesthesia. Anesth. Clin. Res., 5: 3, 2014.

15- BAJAJ J., MITTAL R.S. and SHARMA A.: Pre-operative clonidine use in trans-sphenoidal pituitary adenoma surgeries-a randomized controlled trial. Br. J. Neurosurg., Aug. 18: 1-3, 2016.

16- MATOT I., KURAS Y. and KRAMER M.R.: Effect of clonidine premedication on haemodynamic responses to fibreoptic bronchoscopy. Anaesthesia, Mar., 55 (3): 26974, 2000. 


\section{تآثير التمهيد الدوائى بعقار الكلوتيدين مقابل الآتينولول

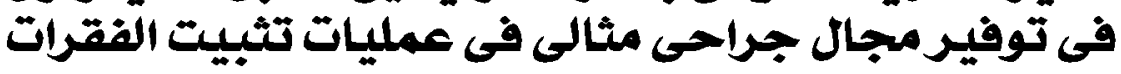

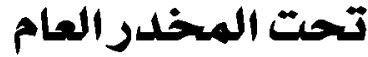

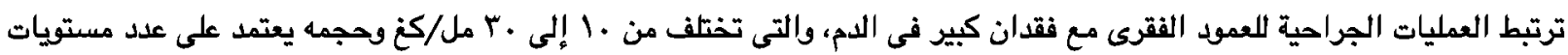

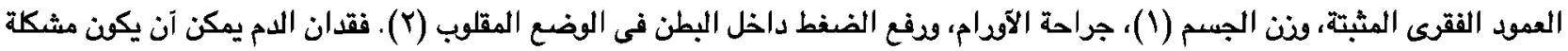

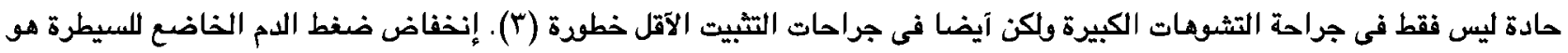

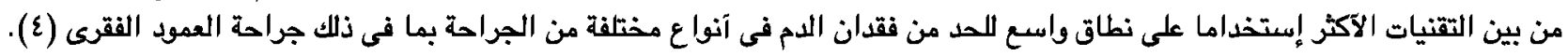

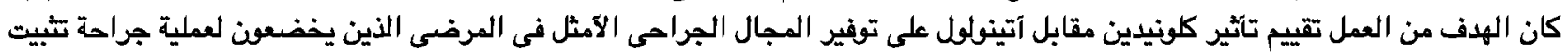

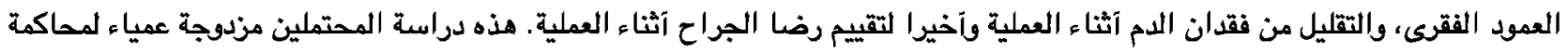

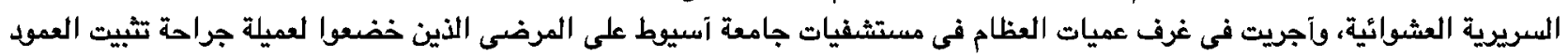

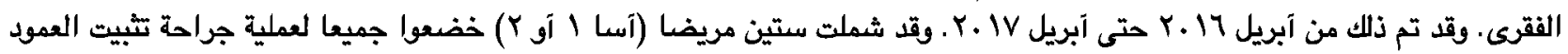

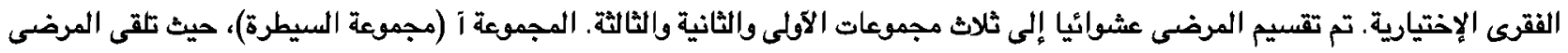

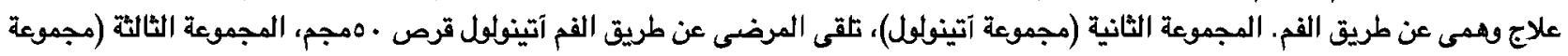

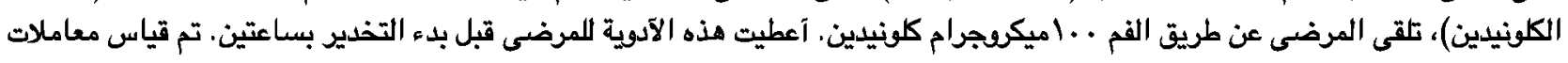

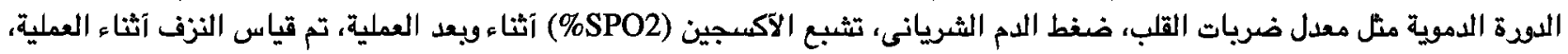

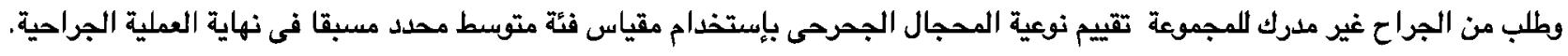

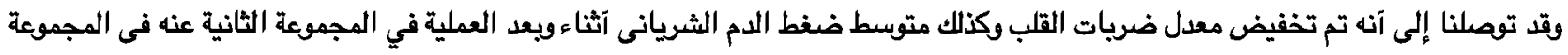

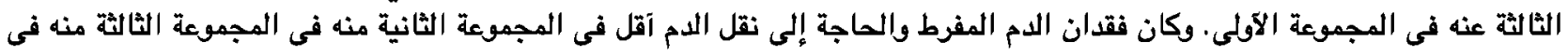

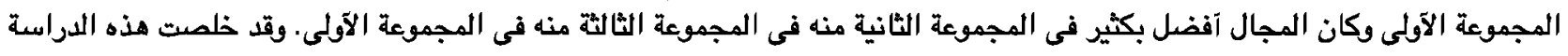

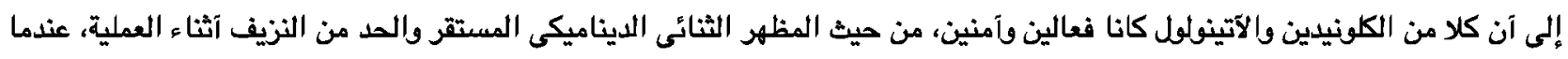

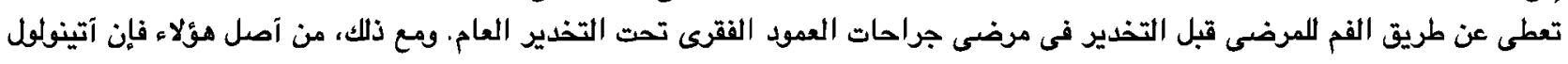

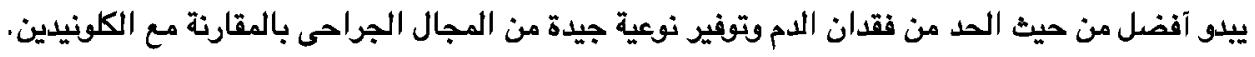

